\title{
Avaliação da reologia, da RAA e das propriedades de argamassas no estado fresco utilizando cinza de eucalipto como substituição parcial ao cimento Portland
}

\author{
Evaluation of mortar rheology, AAR and properties, in \\ fresh state, using eucalyptus ash as partial replacement \\ to Portland cement
}

\begin{tabular}{|c|c|}
\hline & $\begin{array}{l}\text { Débhora Flávia Soto França } \\
\text { Rafaela Oliveira Rey } \\
\text { Luciano Renato Conceição Ferreira } \\
\text { Daniel Veras Ribeiro }\end{array}$ \\
\hline & 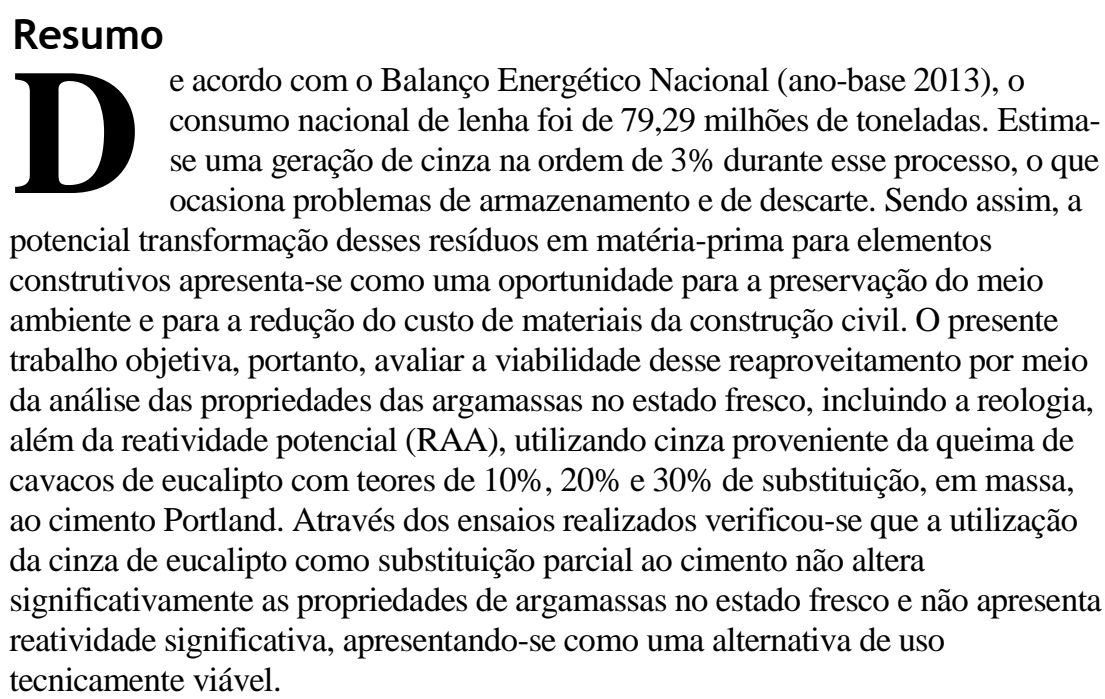 \\
\hline $\begin{array}{l}\text { Universidade Federal da Bahia } \\
\text { Salvador - BA - Brasil }\end{array}$ & $\begin{array}{l}\text { Palavras-chaves: Cinza de eucalipto. Argamassa. Reologia. RAA. Propriedades. } \\
\text { Abstract }\end{array}$ \\
\hline $\begin{array}{r}\text { Rafaela Oliveira Rey } \\
\text { Universidade Federal da Bahia } \\
\text { Salvador - BA - Brasil }\end{array}$ & $\begin{array}{l}\text { According to the National Energy Balance (base year 2013), the national wood } \\
\text { consumption was } 79.29 \text { million tons. It is estimated an ash generation in the order } \\
\text { of } 3 \% \text { during this process, causing storage and disposal problems. Thus, the }\end{array}$ \\
\hline $\begin{array}{r}\text { Luciano Renato Conceição } \\
\text { Ferreira } \\
\text { Universidade Federal da Bahia } \\
\text { Salvador - BA - Brasil }\end{array}$ & $\begin{array}{l}\text { potential transformation of such waste into a source of raw material for } \\
\text { construction elements is presented as an opportunity for the preservation of the } \\
\text { environment and to reduce the cost of construction materials. The paper aims, } \\
\text { therefore, to evaluate the feasibility of this reuse, through analyses of the }\end{array}$ \\
\hline $\begin{array}{r}\text { Daniel Veras Ribeiro } \\
\text { Universidade Federal da Bahia } \\
\text { Salvador - BA - Brasil }\end{array}$ & $\begin{array}{l}\text { properties of mortars in the fresh state, including rheology, using eucalyptus ash } \\
\text { levels with } 10 \%, 20 \% \text { and } 30 \% \text { replacement, in weight, to Portland cement. } \\
\text { Through the performed experiments it was found that the use of eucalyptus ash as } \\
\text { partial replacement of cement does not significantly alter the properties of fresh } \\
\text { mortars, presenting itself as a possible alternative. }\end{array}$ \\
\hline $\begin{array}{r}\text { Recebido em 17/06/15 } \\
\text { Aceito em 04/03/16 }\end{array}$ & alyptus ash. Mortar. Rheology. AAR. Properties. \\
\hline
\end{tabular}

FRANÇA, D. F. S.; REY, R. O.; FERREIRA, L. R. C.; RIBEIRO, D. V. Avaliação da reologia, da RAA e das propriedades de argamassas no estado fresco utilizando cinza de eucalipto como substituição parcial ao cimento Portland. Ambiente Construído, Porto Alegre, v. 16, n. 3, p. 153-166, jul./set. 2016.

ISSN 1678-8621 Associação Nacional de Tecnologia do Ambiente Construído. http://dx.doi.org/10.1590/s1678-86212016000300098 


\section{Introdução}

O processo de produção do cimento Portland, além de ser um grande consumidor dos recursos naturais do planeta, é responsável por cerca de $5 \%$ a $8 \%$ das emissões mundiais de $\mathrm{CO}_{2}$ na atmosfera (SCRIVENER; KIRKPATRICK, 2007). De acordo com o Sindicato Nacional da Indústria do Cimento (2014), para cada tonelada de cimento produzido no mundo emitem-se entre $600 \mathrm{~kg}$ e 900 $\mathrm{kg}$ de $\mathrm{CO}_{2}$, o que torna a indústria cimenteira a segunda maior produtora de gases do efeito estufa. Assim, é cada vez maior a pressão sobre as indústrias de construção pela adoção de práticas consideradas ambientalmente adequadas ou sustentáveis. Uma possibilidade é a redução da fabricação do cimento mediante a utilização de materiais pozolânicos, tais como sílica ativa, cinza volante e cinzas de biomassa, como materiais cimentícios suplementares (MCS).

O resíduo avaliado neste trabalho é a cinza de eucalipto, proveniente da queima dos cavacos de eucalipto para geração de energia através da biomassa. De acordo com o Balanço Energético Nacional (ano-base 2013) (BALANÇO..., 2014), o consumo nacional de lenha foi de 79,29 milhões de toneladas e estima-se uma geração de cinza na ordem de $3 \%$ durante esse processo, ocasionando problemas de armazenamento e de descarte. Portanto, a quantidade crescente de cinza produzida em todo o mundo implica uma reciclagem necessária não só devido aos custos de deposições em aterros, que, por sua vez, refletem sobre o custo da energia produzida, mas também como uma consequência da política "zero-waste" (resíduo zero), que deve ser a meta final de todas as futuras atividades humanas (MASCHIO et al., 2011).

Estudos recentes mostram que o uso de cinzas volantes e de biomassa como materiais cimentícios suplementares melhora as propriedades no estado fresco e no endurecido, e a durabilidade de concretos e argamassas (MASCHIO et al., 2011; KWAN; LI, 2013; BARBOSA et al., 2013; WANG; BAXTER, 2007). Se o MCS for mais fino que o cimento, como é o caso da cinza de eucalipto utilizada nos trabalhos citados, sua incorporação, além de preencher os espaços vazios entre as partículas de cimento, irá aumentar o empacotamento dos concretos e das argamassas, melhorando seu desempenho no estado fresco (MASCHIO et al., 2011).

Diversos trabalhos (VASKE, 2012; RESENDE, 2013; SILVA et al., 1993) têm avaliado a viabilidade da incorporação da cinza de eucalipto nas matrizes cimentícias. De maneira geral, os resultados obtidos por esses autores mostraram que a cinza de eucalipto pode ser utilizada em adição ou substituição, em massa, ao cimento Portland nas argamassas e concretos, acarretando na melhora do desempenho mecânico devido ao efeito fíller, além de ser uma alternativa ambientalmente adequada para a destinação desse resíduo.

$\mathrm{O}$ presente trabalho consistiu em avaliar a viabilidade técnica do uso de cinza de eucalipto como material cimentício suplementar, por meio da caracterização física, química e mineralógica do resíduo e da análise do desempenho no estado fresco das argamassas utilizando cinza de eucalipto com $10 \%, 20 \%$ e $30 \%$ de substituição, em massa, ao cimento Portland.

\section{Materiais e métodos \\ Materiais}

Para a confecção das argamassas foi utilizado cimento CP V ARI RS, areia natural quartzosa e água proveniente da rede pública de abastecimento da Empresa Baiana de Água e Saneamento S.A. (Embasa). A cinza de eucalipto produzida por uma indústria da cidade de Alagoinhas, BA, foi gerada durante a queima da biomassa de eucalipto para produção de energia, em uma temperatura de aproximadamente $450{ }^{\circ} \mathrm{C}$, sendo classificada como cinza leve ou volante. O resíduo foi peneirado em laboratório em peneira com abertura de $300 \mu \mathrm{m}$, com o intuito de eliminar partículas grosseiras e de se obter um material mais uniforme. Utilizou-se, ainda, um agregado natural de alta reatividade, encontrado na região de Feira de Santana, BA, com o qual foram feitos os ensaios de reação álcalis-agregado.

\section{Métodos}

\section{Caracterização das matérias-primas}

A análise granulométrica da areia e a determinação do módulo de finura foram realizadas através do peneiramento manual, segundo a NBR 7211 (ABNT, 2009), e a massa específica foi determinada pelo método do frasco de Chapman, segundo a NBR 9776 (ABNT, 1987).

A caracterização física do cimento e da cinza de eucalipto consistiu na análise da distribuição do tamanho de partículas por meio de sedígrafo a laser (Horiba CAPA-700 e Mastersizer 2000 Malvern respectivamente). As amostras em análise foram dispersas em óleo mineral Tegiloxan $3 \mathrm{e}$ rotacionadas a $2.000 \mathrm{rpm}$ para que as amostras ficassem em dispersão. Avaliou-se, ainda, a massa específica por picnometria a gás hélio (AccuPyc II

154 França, D. F. S.; Rey, R. O.; Ferreira, L. R. C.; Ribeiro, D. V. 
1340 Micromeritics), área superficial específica BET (Gemini 2370 V1.02, da Micrometrics) e Blaine, de acordo com a NBR NM 76 (ABNT, 1998), e as composições químicas foram determinadas por meio de fluorescência de raios $\mathrm{X}$ (FRX).

A caracterização mineralógica da cinza de eucalipto foi obtida por difração de raios X (DRX), utilizando-se o método do pó e empregando-se um difratômetro Bruker D2 Phaser com radiação $\mathrm{CuK} \alpha$, tensão de $30 \mathrm{KV}$, corrente de $10 \mathrm{~mA}$, filtro de níquel e sem monocromador, incremento de $0,04^{\circ}$ por segundo, com ângulo $2 \theta$ de varredura entre $5^{\circ}$ e $80^{\circ}$. Na identificação das fases utilizouse o software Diffrac Eva Plus 3.2, com banco de dados JCPDS.

\section{Determinação da reatividade da cinza de eucalipto devido à RAA}

O método utilizado para avaliar a reatividade da cinza de eucalipto quanto à reação álcalis-agregado (RAA) foi o definido pela norma NBR 15577-4 (ABNT, 2008a). Esse método consiste em avaliar a expansão dimensional de barras de argamassa submetidas a uma solução alcalina de hidróxido de sódio a $80^{\circ} \mathrm{C}$.

Para o preparo da argamassa, o agregado deve ser obtido com um mínimo de britagem, de forma a produzir um produto classificado conforme a norma. Foram moldadas barras de dimensão 25 $\mathrm{mm}$ x $25 \mathrm{~mm}$ x $285 \mathrm{~mm}$ com proporção cimento:agregado normatizada e igual a 1:2,25 com relação a/c fixada, também pela norma, igual a 0,47. Foi utilizado o cimento CP V - ARI RS e optou-se por substituir-se parcialmente o cimento pela cinza de eucalipto, pois as características do material indicam a possibilidade de reatividade quanto à RAA devido à alta concentração de álcalis em sua composição. A cinza foi utilizada nos teores de $10 \%$ e $20 \%$.

\section{Formulação e preparo das argamassas}

Definiu-se, a princípio, o traço de referência de 1,00:2,60:0,66 (cimento:areia:água), em que parte do cimento foi substituída, em massa, por cinza de eucalipto, nos teores de $10 \%, 20 \%$ e $30 \%$, e a relação entre água e materiais sólidos $(\mathrm{a} / \mathrm{ms})$ foi mantida constante $(0,183)$ para parâmetro de controle. Entretanto, em avaliação reológica preliminar por meio do reômetro, foi possível ensaiar apenas as argamassas de referência e com teor de $10 \%$ de substituição, uma vez que as argamassas com os teores de $20 \%$ e $30 \%$ atingiram o torque máximo do equipamento $(150 \mathrm{mN} . \mathrm{m})$, indicando que estavam muito consistentes e que seria preciso mais força (torque) para rotacionálas. Portanto, para que as propriedades reológicas de todas as argamassas fossem analisadas, foi necessário aumentar a relação a/ms delas para 0,194 , resultando nas relações a/c apresentadas na Tabela 1 (traço 2).

\section{Análise de desempenho}

Densidade de massa e teor de ar incorporado

$\mathrm{O}$ teor de ar incorporado exerce influência direta sobre a densidade de massa das argamassas no estado fresco e é dado pela quantidade de ar aprisionado nelas (NAKAKURA; CINCOTTO, 2004). O método de ensaio é dado pela NBR 13278 (ABNT, 2005b).

\section{Índice de retenção de água}

A retenção de água está associada à capacidade da argamassa de não perder sua trabalhabilidade quando submetida à evaporação, reações de hidratação e sucção do substrato (ALVES; DO Ó, 2005). Para que as reações químicas de endurecimento dos ligantes ocorram de maneira adequada, as argamassas devem possuir capacidade mínima de retenção de água (CARASEK, 2007). O ensaio é definido segundo a NBR 13277 (ABNT, 2005a).

Tabela 1 - Formulação das argamassas utilizadas no presente estudo (o traço 2 foi utilizado apenas para ensaios com o reômetro)

\begin{tabular}{|c|c|c|c|c|c|c|}
\hline \multirow[b]{2}{*}{$\begin{array}{c}\text { Teores de } \\
\text { substituição }\end{array}$} & \multicolumn{3}{|c|}{ Traço 1} & \multicolumn{3}{|c|}{ Traço 2} \\
\hline & $\mathrm{a} / \mathrm{c}$ & $\mathrm{a} / \mathrm{ms}$ & $\begin{array}{c}\text { Água/ } \\
\text { (cimento+cinza) }\end{array}$ & $a / c$ & $\mathrm{a} / \mathrm{ms}$ & $\begin{array}{c}\text { Água/ } \\
\text { (cimento+cinza) }\end{array}$ \\
\hline $0 \%$ & 0,66 & \multirow{4}{*}{0,183} & \multirow{4}{*}{0,66} & 0,70 & \multirow{4}{*}{0,194} & \multirow{4}{*}{0,70} \\
\hline $10 \%$ & 0,73 & & & 0,77 & & \\
\hline $20 \%$ & 0,82 & & & 0,87 & & \\
\hline $30 \%$ & 0,94 & & & 1,00 & & \\
\hline
\end{tabular}




\section{Avaliação reológica por meio da mesa de consistência (flow table)}

Por meio da mesa de consistência é possível avaliar o espalhamento horizontal de uma argamassa após esta ser submetida a uma série de impactos (KOEHLER; FOWLER, 2003). De acordo com a NBR 13276 (ABNT, 2010), o material é inicialmente colocado em um molde troncocônico, e, após a retirada do molde, são aplicados 30 golpes na mesa de teste. Imediatamente após o último golpe mede-se o diâmetro de espalhamento da argamassa, sendo o índice de consistência dado pelo diâmetro médio de espalhamento. Quanto maior for o índice de consistência, mais fluida é a argamassa e, consequentemente, maior sua plasticidade.

Entretanto, o comportamento reológico de uma argamassa não pode ser descrito apenas pelo valor obtido no índice de consistência, pois é possível que duas argamassas obtenham resultados iguais desse parâmetro e comportamentos completamente diferentes na prática, a ponto de uma delas apresentar excelente trabalhabilidade e a outra chegar ao ponto de não ser aplicável (CARASEK, 2007). Sendo assim, faz-se necessária a elaboração de um perfil reológico medido com precisão, que simule as práticas reais de solicitação (CARDOSO, 2009).

\section{Avaliação reológica por meio de reometria}

Por meio da reometria rotacional é possível a determinação dos dois parâmetros fundamentais para o estudo reológico das argamassas, a viscosidade e a tensão de escoamento, superando os ensaios que fornecem apenas um resultado pontual, como o flow table. O funcionamento do reômetro se dá através de dois princípios: aplica-se o torque e mede-se o cisalhamento resultante; ou controla-se o cisalhamento aplicado (MASCHIO, 2011). O reômetro utilizado no presente trabalho foi o do tipo rotacional, Rheotest Medingen $\mathrm{GmbH}$ - RN 4.1. Depois da mistura, as argamassas foram ensaiadas no reômetro por $47 \mathrm{~min}$, com uma velocidade de rotação máxima de $150 \mathrm{rpm}$. A rotina estabelecida para a análise das argamassas é apresentada na Figura 1.

De acordo com diversos estudos (SENFF; HOTZA; REPETTE, 2010), as argamassas, quando em estado fresco, podem ser consideradas fluidos descritos pelo modelo de Bingham, ou seja, materiais que apresentam relação linear entre tensão e taxa de cisalhamento, porém necessitam de uma tensão mínima de cisalhamento para que se inicie o escoamento (tensão de escoamento). Para o caso de reômetros que medem o torque em função da frequência de rotação, o modelo de Bingham, inicialmente descrito segundo a Equação 1, pode ser adaptado para a Equação 2 onde $T$ é o torque, e $g$ (N.mm) e $h$ (N.mm.min) são constantes características do material, proporcionais à tensão de escoamento $\left(\tau_{0}\right)$ e à viscosidade plástica $(\mu)$ respectivamente.

$\tau=\tau_{0}+\mu \cdot \gamma$

Eq. 1

$T=g+h . N$

Eq. 2

Onde:

$\tau$ a tensão de cisalhamento;

$\gamma$ a taxa de cisalhamento; e

$\mathrm{N}$ a frequência de rotação (rpm) do equipamento.

Figura 1 - Rotina de frequência, em função do tempo, utilizada nos ensaios de reometria

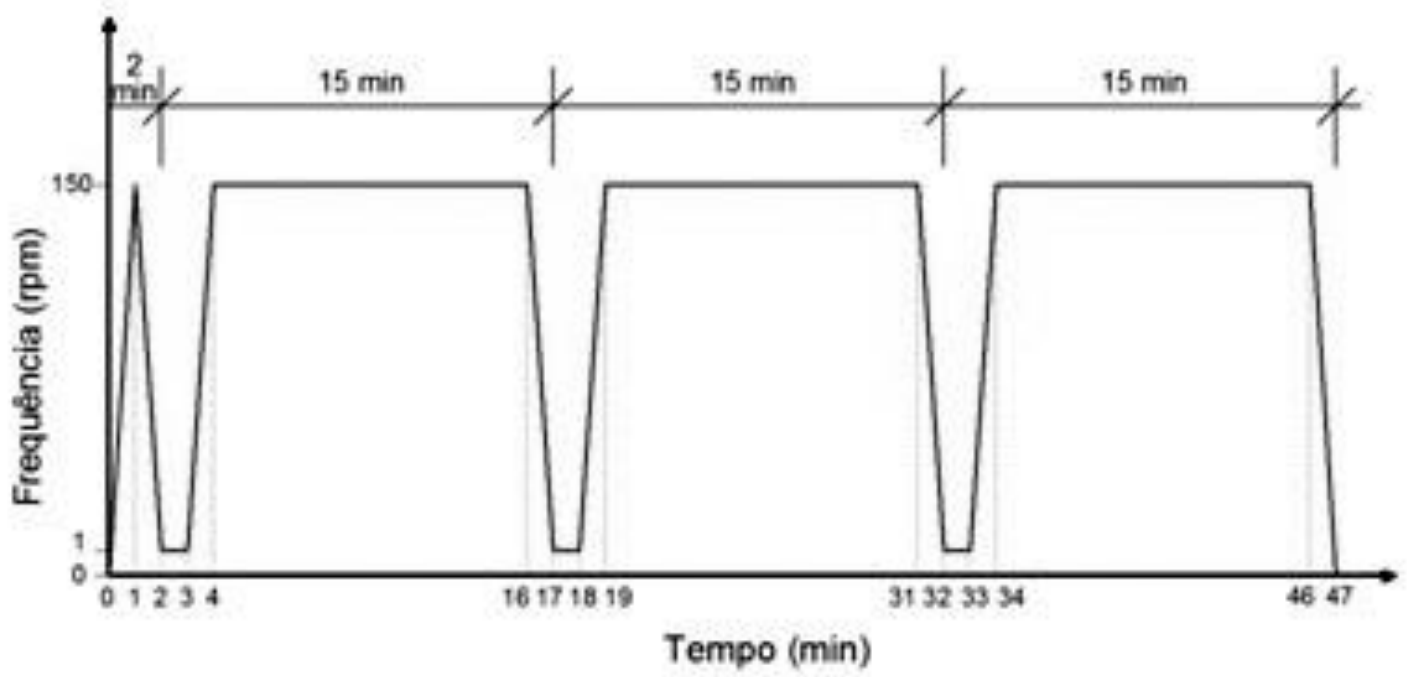

156 França, D. F. S.; Rey, R. O.; Ferreira, L. R. C.; Ribeiro, D. V. 
No segundo minuto de ensaio e a cada $15 \mathrm{~min}$, quando a velocidade é reduzida de $150 \mathrm{rpm}$ até o repouso, é possível obter uma reta de tendência na curva de retorno, sobre a qual se aplica o modelo de Bingham, de acordo com a Figura 2. O valor de $\mathrm{g}$ é representado pelo coeficiente linear, enquanto $\mathrm{h}$ é dado pelo coeficiente angular da reta obtida.

\section{Resultados e discussão}

\section{Caracterização das matérias-primas}

As distribuições dos tamanhos dos grãos da areia, cimento e cinza são exibidas na Figura 3. A areia utilizada apresentou módulo de finura de 1,32, dimensão máxima característica de $1,18 \mathrm{~mm}$, diâmetro médio $\left(\mathrm{D}_{50}\right)$ de $0,270 \mathrm{~mm}$, massa específica de $2,66 \mathrm{~g} / \mathrm{cm}^{3}$ e teor de material pulverulento igual a $0,50 \%$.

O cimento utilizado, CP V ARI RS, de acordo com a norma NBR 5733 (ABNT, 1991), apresentou massa específica de $3,167 \mathrm{~g} / \mathrm{cm}^{3}$, área superficial específica Blaine de $4.466 \mathrm{~cm}^{2} / \mathrm{g}$ e área superficial específica BET de $8.924 \mathrm{~cm}^{2} / \mathrm{g}$. Sua composição química é informada na Tabela 2.

Figura 2 - Modelo de Bingham, utilizado na determinação dos parâmetros $\mathrm{g}$ e $\mathrm{h}$ das argamassas

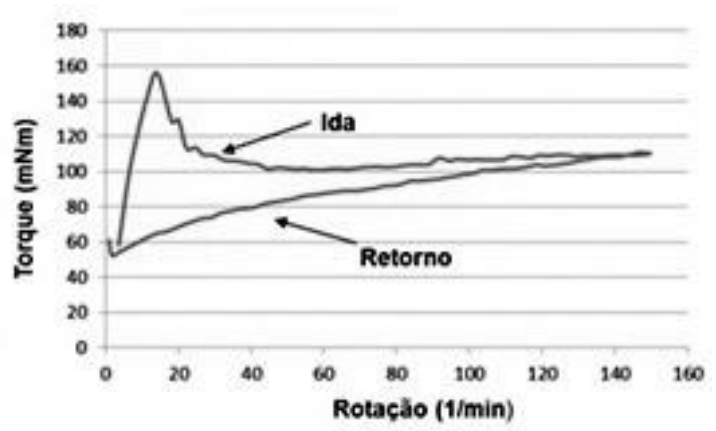

(a) Exemplo de aceleração e desaceleração do reômetro

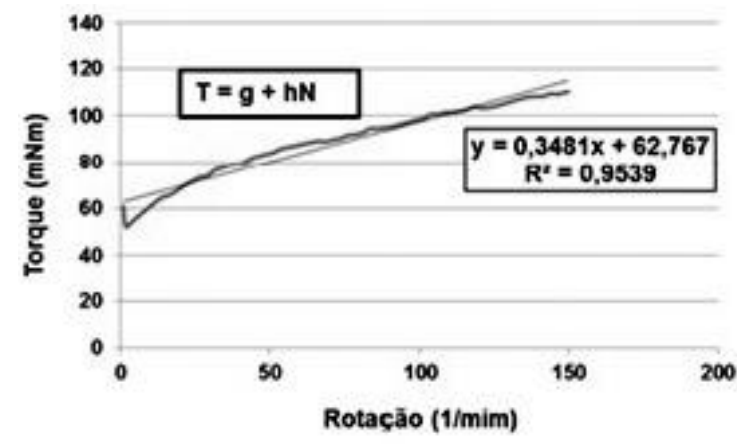

(b) Reta de tendência durante o período de desaceleração (retorno) do reômetro

Figura 3 - Distribuição do tamanho de partículas do cimento Portland CP V ARI RS, da cinza de eucalipto e da areia

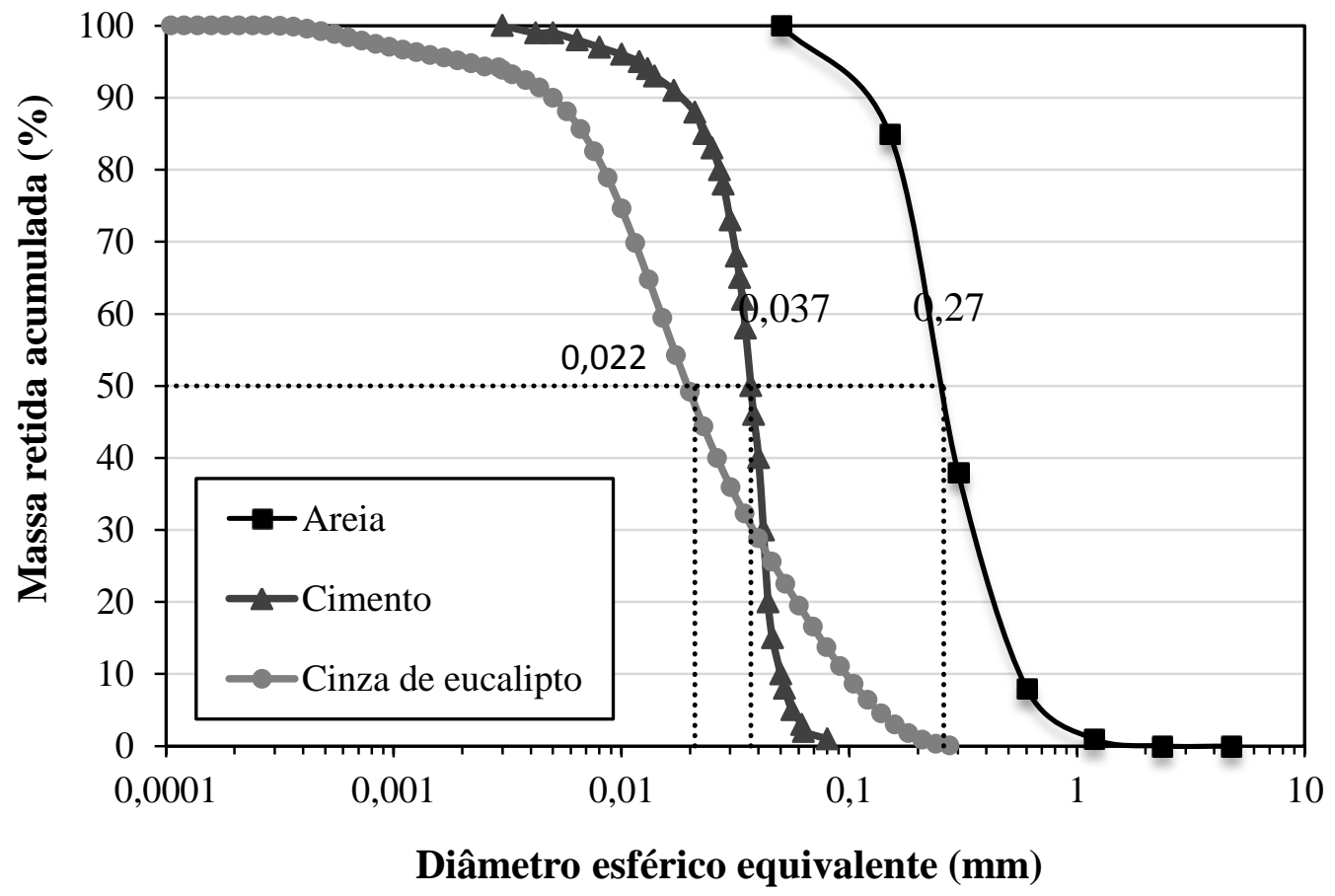


Tabela 2 - Composição química do cimento CP V ARI RS, obtida por FRX, em \%

\begin{tabular}{|c|c|c|c|c|c|c|c|c|}
\hline \multirow{2}{*}{$\mathrm{CaO}$} & \multirow{2}{*}{$\mathrm{SiO}_{2}$} & \multirow{2}{*}{$\mathrm{Al}_{2} \mathrm{O}_{3}$} & \multirow{2}{*}{$\mathrm{SO}_{3}$} & \multirow{2}{*}{$\mathrm{Fe}_{2} \mathrm{O}_{3}$} & \multirow{2}{*}{ MgO } & \multicolumn{3}{|c|}{ Álcalis } \\
\hline & & & & & & $\mathrm{Na}_{2} \mathrm{O}$ & $\mathrm{K}_{2} \mathrm{O}$ & Na2Oeq* \\
\hline 61,12 & 19,10 & 4,84 & 3,35 & 3,19 & 2,73 & 0,24 & 0,70 & 0,706 \\
\hline
\end{tabular}

Nota: ${ }^{*} \mathrm{Na}_{2} \mathrm{Oeq}=0,658 \cdot \mathrm{K}_{2} \mathrm{O}+\mathrm{Na}_{2} \mathrm{O}$.

A cinza de eucalipto apresentou massa específica de $2,42 \mathrm{~g} / \mathrm{cm}^{3}$, área superficial específica Blaine de $6.415 \mathrm{~cm}^{2} / \mathrm{g}$ e área superficial específica BET de $27.573 \mathrm{~cm}^{2} / \mathrm{g}$. Na Figura 3 foram apresentadas as curvas granulométricas da areia, do cimento e da cinza de eucalipto. $\mathrm{O}$ cimento apresentou diâmetro médio de partículas $\left(\mathrm{D}_{50}\right)$ em torno de $0,037 \mathrm{~mm}$, enquanto o $\mathrm{D}_{50}$ da cinza de eucalipto ficou em torno de 0,022 mm. É possível perceber que a cinza de eucalipto é mais fina que o cimento, em conformidade com a maior área superficial específica encontrada, e possui uma curva contínua de distribuição, o que também pode ser visto na microscopia apresentada na Figura 4. Esta característica é positiva quanto à adição a matrizes cimentícias, pois, para uma melhor densidade de empacotamento, o sistema deve conter uma ampla variedade de tamanhos de partículas, de forma que as partículas de tamanho menor preencham as partículas de tamanho médio, e assim sucessivamente. Além disso, percebe-se a predominância de formatos aproximadamente cúbicos e prismáticos, o que leva a uma maior densidade de empacotamento das argamassas, pois menor é a fricção entre as partículas, o que pode ser ocasionada pelo contato de superfícies irregulares de partículas não esféricas (OLIVEIRA et al., 2000).

Devido à elevada finura das cinzas $\left(27.573 \mathrm{~cm}^{2} / \mathrm{g}\right)$, em comparação às partículas de cimento (8.924 $\mathrm{cm}^{2} / \mathrm{g}$ ), é necessária maior quantidade de água para o molhamento dessas partículas, conforme observado nos valores de relação a/c apresentados na Tabela 1. Além disso, uma vez que a substituição do cimento pelas cinzas foi feita em massa e estes materiais apresentam massas específicas diferentes $\left(3,167 \mathrm{~kg} / \mathrm{dm}^{3}\right.$ para o cimento e $2,42 \mathrm{~kg} / \mathrm{dm}^{3}$ para as cinzas), os consumos de materiais foram significativamente alterados. O consumo de materiais por metro cúbico $\left(\mathrm{kg} / \mathrm{m}^{3}\right)$ é apresentado na Tabela 3 .

A composição química das cinzas é apresentada na Tabela 4, onde é possível observar a predominância de sílica $\left(\mathrm{SiO}_{2}\right)$ e de óxido de cálcio $(\mathrm{CaO})$ como principais constituintes. Observa-se também que o teor de álcalis equivalente $\left(\mathrm{Na}_{2} \mathrm{Oeq}\right.$, igual $0,730 \%$ ) das cinzas é muito semelhante ao encontrado no cimento CP V ARI RS (igual a $0,706 \%)$

\section{Figura 4 - Micrografia da cinza de eucalipto, obtida por meio de microscopia eletrônica de varredura} (MEV)
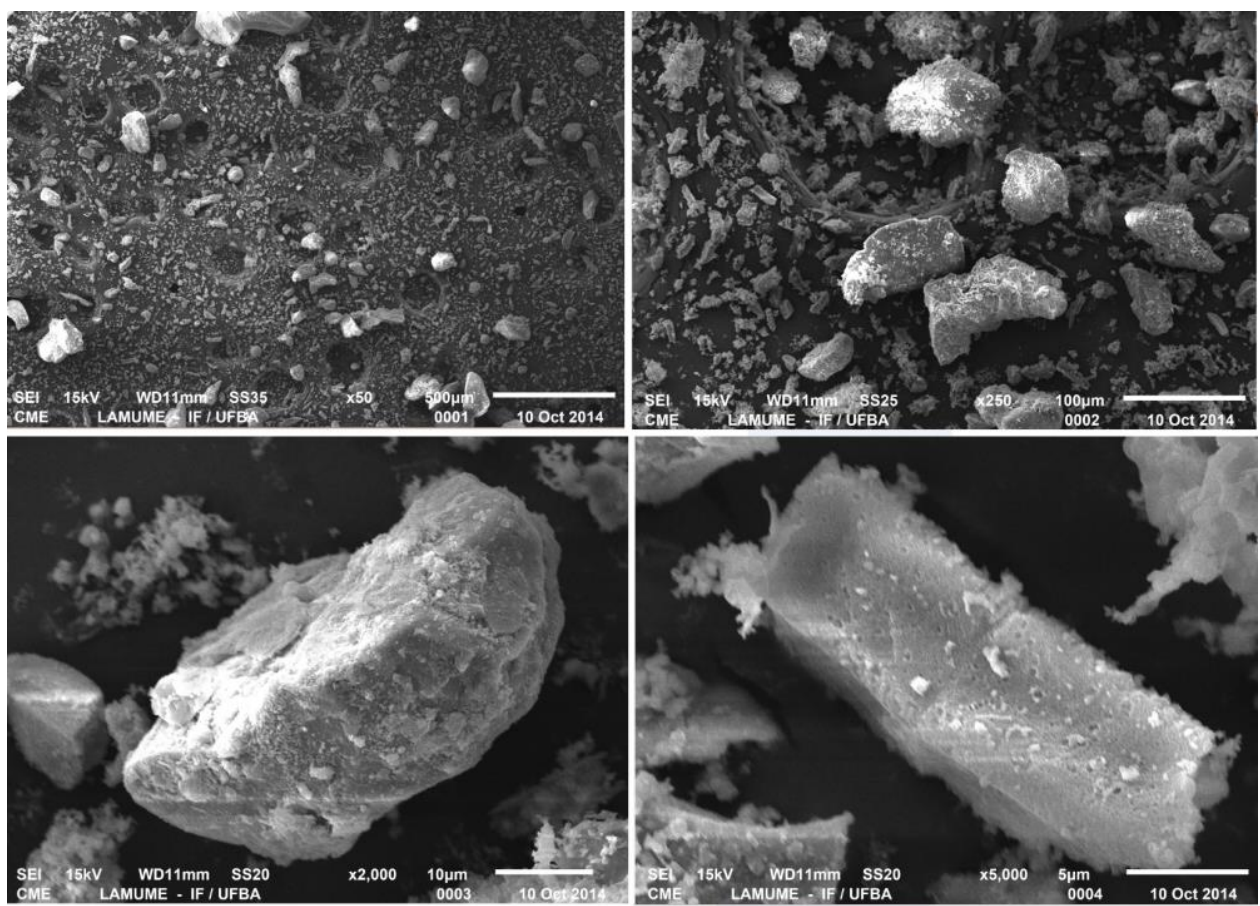

158 França, D. F. S.; Rey, R. O.; Ferreira, L. R. C.; Ribeiro, D. V. 
Tabela 3 - Consumo dos materiais por metro cúbico de argamassa em massa $\left(\mathrm{kg} / \mathrm{m}^{3}\right)$ e em volume $\left(\mathrm{dm}^{3} / \mathrm{m}^{3}\right)$

\begin{tabular}{|c|c|c|c|c|c|c|c|c|}
\hline \multirow{2}{*}{$\begin{array}{c}\text { Teores de } \\
\text { substituição }\end{array}$} & \multicolumn{4}{|c|}{ Traço $1\left(\mathrm{~kg} / \mathrm{m}^{3}\right)$} & \multicolumn{4}{|c|}{ Traço $2\left(\mathrm{~kg} / \mathrm{m}^{3}\right)$} \\
\hline & Cimento & Cinzas & Areia & Água & Cimento & Cinzas & Areia & Água \\
\hline $0 \%$ & 511,98 & 0,00 & $1.331,15$ & 337,91 & 501,71 & 0,00 & $1.304,44$ & 351,19 \\
\hline $10 \%$ & 460,78 & 51,20 & $1.331,15$ & 337,91 & 451,54 & 50,17 & $1.304,44$ & 351,19 \\
\hline $20 \%$ & 409,58 & 102,40 & $1.331,15$ & 337,91 & 401,36 & 100,34 & $1.304,44$ & 351,19 \\
\hline $30 \%$ & 358,39 & 153,59 & $1.331,15$ & 337,91 & 351,19 & 150,51 & $1.304,44$ & 351,19 \\
\hline \multirow{2}{*}{$\begin{array}{c}\text { Teores de } \\
\text { substituição }\end{array}$} & \multicolumn{4}{|c|}{ Traço $1\left(\mathrm{dm}^{3} / \mathrm{m}^{3}\right)$} & \multicolumn{4}{|c|}{ Traço $2\left(\mathrm{dm}^{3} / \mathrm{m}^{3}\right)$} \\
\hline & Cimento & Cinzas & Areia & Água & Cimento & Cinzas & Areia & Água \\
\hline $0 \%$ & 161,66 & 0,00 & 500,43 & 337,91 & 158,42 & 0,00 & 490,39 & 351,19 \\
\hline $10 \%$ & 145,49 & 21,16 & 500,43 & 337,91 & 142,58 & 20,73 & 490,39 & 351,19 \\
\hline $20 \%$ & 129,33 & 42,31 & 500,43 & 337,91 & 126,73 & 41,46 & 490,39 & 351,19 \\
\hline $30 \%$ & 113,16 & 63,47 & 500,43 & 337,91 & 110,89 & 62,19 & 490,39 & 351,19 \\
\hline
\end{tabular}

Tabela 4 - Composição química das cinzas de eucalipto, obtida por FRX, em \%

\begin{tabular}{|c|c|c|c|c|c|c|c|c|c|c|c|}
\hline \multirow{2}{*}{$\mathrm{SiO}_{2}$} & \multirow{2}{*}{$\mathrm{CaO}$} & \multirow{2}{*}{$\mathrm{TiO}_{2}$} & \multirow{2}{*}{$\mathbf{A l}_{2} \mathbf{O}_{3}$} & \multirow{2}{*}{ MnO } & \multirow{2}{*}{$\mathrm{ZnO}$} & \multirow{2}{*}{$\mathrm{CuO}$} & \multirow{2}{*}{$\mathbf{B r}$} & \multirow{2}{*}{$\mathrm{Cr}_{2} \mathrm{O}_{3}$} & \multicolumn{3}{|c|}{ Álcalis } \\
\hline & & & & & & & & & $\mathrm{Na}_{2} \mathrm{O}$ & $\mathbf{K}_{2} \mathbf{O}$ & $\mathrm{Na}_{2} \mathrm{Oeq}^{*}$ \\
\hline 64,41 & 15,02 & 5,82 & 5,47 & 2,97 & 2,62 & 1,11 & 1,05 & 0,42 & $\mathrm{Nd}$ & 1,11 & 0,730 \\
\hline
\end{tabular}

Nota: ${ }^{*} \mathrm{Na}_{2} \mathrm{Oeq}=0,658 \cdot \mathrm{K}_{2} \mathrm{O}+\mathrm{Na}_{2} \mathrm{O}$.

Pelo difratograma de raios X (Figura 5) é possível identificar as fases cristalográficas desse material, quando obtido pela queima do eucalipto em torno de $450{ }^{\circ} \mathrm{C}$. Percebe-se a predominância de quartzo $\left(\mathrm{SiO}_{2}\right)$, tipicamente produzido durante o processo de combustão da biomassa, e calcita (carbonato de cálcio), proveniente da madeira utilizada na queima, conforme também foi observado por Cabrera et al. (2014), apesar de este autor não informar a temperatura de queima desse material. As cinzas estudadas apresentaram predominância da fase cristalina (86\%), o que pode contribuir para uma baixa reatividade, devendo apresentar baixa atividade pozolânica, uma vez que não sofrerá nenhuma moagem posterior.

\section{Determinação da reatividade devido à RAA da cinza de eucalipto}

Devido à elevada finura das cinzas, ao elevado teor de sílica e ao teor de álcalis, semelhantes ao cimento Portland, optou-se por avaliar sua reatividade. A Figura 6 apresenta os resultados dos ensaios de reação álcalis-agregado obtidos por meio do ensaio normatizado pela NBR 15577-1 (ABNT, 2008b). De acordo com a referida norma, quando o resultado obtido no ensaio acelerado das barras de argamassa (NBR 15577-4a) indicar expansão superior a $0,19 \%$, o agregado pode ser considerado reativo para uso em concreto. Para este ensaio, utilizou-se um agregado de alta reatividade, a fim de avaliar o potencial reativo das cinzas.
Como era de se esperar, as amostras de referência superaram os limites estabelecidos pela norma (expansão de 0,27\%), e as argamassas contendo a cinza de eucalipto como substituta parcial ao cimento Portland e o agregado reativo apresentaram expansão máxima de $0,30 \%$ e de $0,28 \%$ para os teores de substituição iguais a $10 \%$ e $20 \%$ respectivamente, superiores aos verificados para a argamassa de referência $(0,27 \%)$, sem cinzas. Assim, observa-se que as cinzas de eucalipto, aos substituírem parcialmente o cimento em teores relevantes $(10 \%$ e $20 \%)$, além de não reduzirem essa expansão, contribuíram para um pequeno aumento desta propriedade e da reatividade álcalis-agregado, diferentemente dos resultados obtidos por Campos (2015), que utilizou cinza de biomassa. No entanto, são necessários estudos mais minuciosos, que envolvam ensaios de longa duração, para que essa reatividade seja ratificada, uma vez que o aumento na reatividade não foi muito significativo.

Uma vez que as características químicas e físicas dos materiais dão um indicativo da reatividade deles, e conforme apresentado nas Tabelas 2 e 4 , observa-se que dois aspectos contribuíram para esses resultados de RAA:

(a) o teor de álcalis equivalente total da cinza

$(0,72 \%)$ é superior ao verificado no cimento

$(0,70 \%)$; e

(b) as cinzas são consideravelmente mais finas que o cimento, apesar da elevada cristalinidade daquelas $(86 \%)$. 
Figura 5 - Difratograma de raios X da cinza de eucalipto

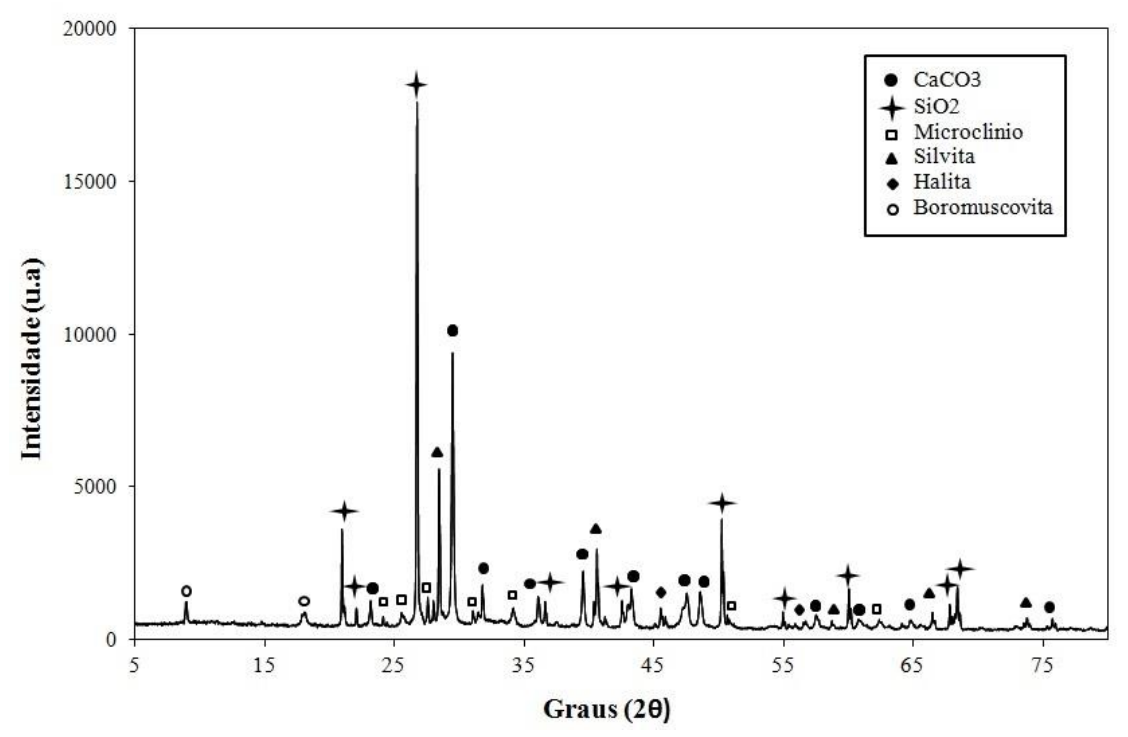

Figura 6 - Expansão devido à reação álcalis-agregado (RAA) das barras de argamassas de referência (0\%) contendo os teores de $10 \%$ e $20 \%$ de cinza de eucalipto em substituição ao cimento Portland

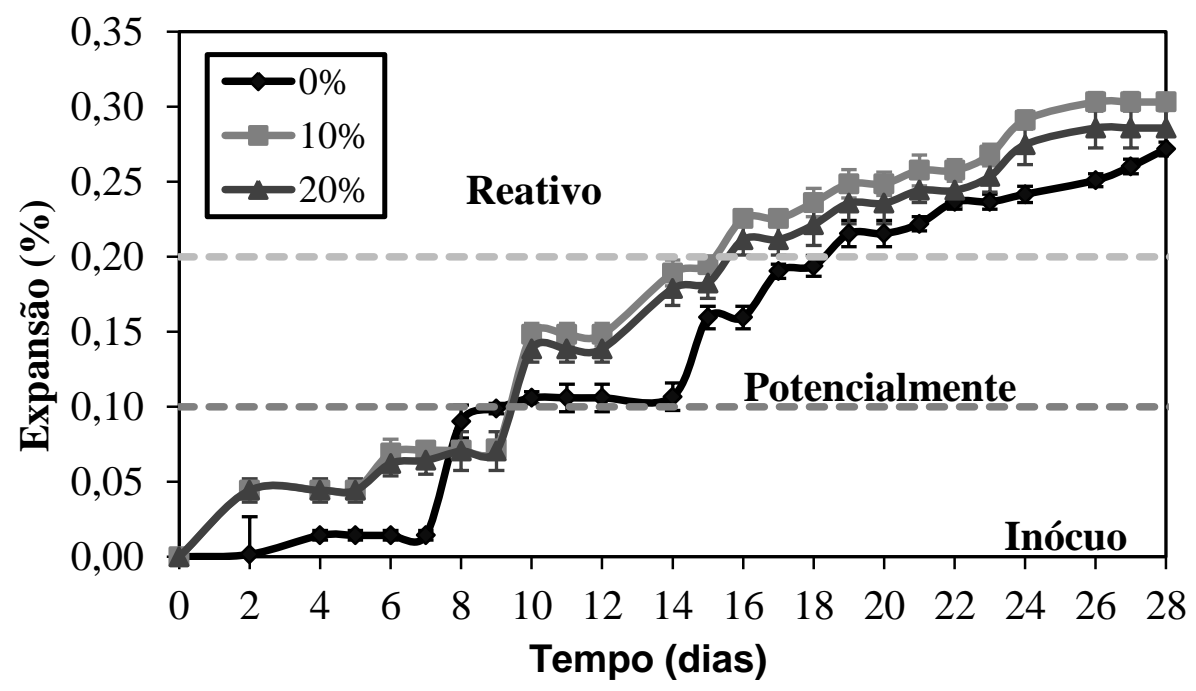

Esses resultados diferem dos obtidos por Shehata e Thomas (2000) e Lodeiro (2007), que realizaram ensaios de expansão com cinzas volantes e observaram que esses materiais possuem capacidade de mitigar a RAA, mesmo contendo concentrações de álcalis elevadas, comprovando que a concentração de álcalis não vem sendo um fator importante para a determinação da reatividade quanto à RAA.

\section{Análise de desempenho das argamassas}

\section{Densidade de massa, teor de ar} incorporado e índice de retenção de água

São apresentados na Tabela 5 os resultados obtidos de densidade de massa, teor de ar incorporado e retenção de água das argamassas estudadas em função do teor de substituição do cimento pela cinza de eucalipto.

As argamassas com substituição apresentaram aumento em seu teor de ar incorporado, o que pode ser explicado pelo menor tamanho das partículas de cinza, o que acarreta heterogeneidade na matriz (partículas finas) e aumento na quantidade total de 
vazios (OLIVEIRA et al., 2000). Já a densidade de massa, que é um parâmetro inversamente proporcional ao teor de ar incorporado, decresce em função do aumento da cinza utilizada.

A influência dos teores de substituição sobre a capacidade de retenção de água das argamassas estudadas não foi significativa. Além disso, todas as argamassas cumpriram o requisito da NBR 13281 (ABNT, 2005c), que exige um índice mínimo de $78 \%$ de retenção de água para argamassas de assentamento e revestimento.

\section{Avaliação reológica por meio da mesa de consistência (flow table)}

Como explanado anteriormente, foi necessário aumentar a relação água/materiais sólidos $(\mathrm{a} / \mathrm{ms})$ do traço inicial para que todas as argamassas fossem avaliadas no reômetro. A Figura 7 apresenta os resultados de índice de consistência obtidos em função do teor de cinza para as argamassas com a/ms igual a $0,183 \mathrm{e} \mathrm{a} / \mathrm{ms}$ igual a 0,194 . Os resultados de espalhamento das argamassas ficaram compreendidos no intervalo de consistência $347 \pm 12 \mathrm{~mm}$ para argamassa com $\mathrm{a} / \mathrm{ms}$ a 0,194 e no de $328 \pm 12 \mathrm{~mm}$ para as argamassas com a/c igual a 0,183. Resultados semelhantes foram obtidos por Park et al. (2005), segundo os quais o aumento do teor de substituição do cimento por partículas mais finas implicou a diminuição do espalhamento das argamassas estudadas, que inicialmente demandaram maior quantidade de água para o molhamento total das partículas.

\section{Avaliação reológica por meio de reometria}

No traço inicialmente proposto (relação água/materiais sólidos igual a 0,183 ) foi possível perceber a formação de aglomerados nas argamassas com substituição, o que fez com que as misturas com $20 \%$ e $30 \%$ de cinza de eucalipto alcançassem o valor do torque máximo do reômetro $(150 \mathrm{mN} . \mathrm{m})$ ainda no início do ensaio. De acordo com Park et al. (2005), materiais finos, como a cinza de eucalipto, quando em contato com água, possuem forte tendência a se aglomerar, aumentando o atrito interno e dificultando o fluxo da mistura, pela maior demanda de água. Com o aumento da relação água/materiais sólidos verificou-se a não formação de aglomerados e foi possível completar os ensaios reométricos de todas as argamassas.

Tabela 5 - Densidade de massa, teor de ar incorporado e índice de retenção de água das argamassas em função do teor de cimento substituído por cinza

\begin{tabular}{c|c|c|c}
\hline $\begin{array}{c}\text { Teor de cinza de } \\
\text { eucalipto }\end{array}$ & $\begin{array}{c}\text { Densidade aparente } \\
\left(\mathbf{g} / \mathbf{c m}^{3}\right)\end{array}$ & $\begin{array}{c}\text { Teor de ar } \\
\text { incorporado }(\%)\end{array}$ & $\begin{array}{c}\text { Índice de retenção de } \\
\text { água }(\boldsymbol{\%})\end{array}$ \\
\hline $0 \%$ & 2,11 & 2,27 & 81,73 \\
$10 \%$ & 2,04 & 5,44 & 84,28 \\
$20 \%$ & 2,00 & 6,75 & 82,84 \\
$30 \%$ & 1,99 & 6,65 & 82,13 \\
\hline
\end{tabular}

Figura 7 - Índice de consistência das argamassas com diferentes relações a/ms em função do teor de cinzas de eucalipto utilizado em substituição ao cimento, obtidos por meio da mesa de consistência (flow table)

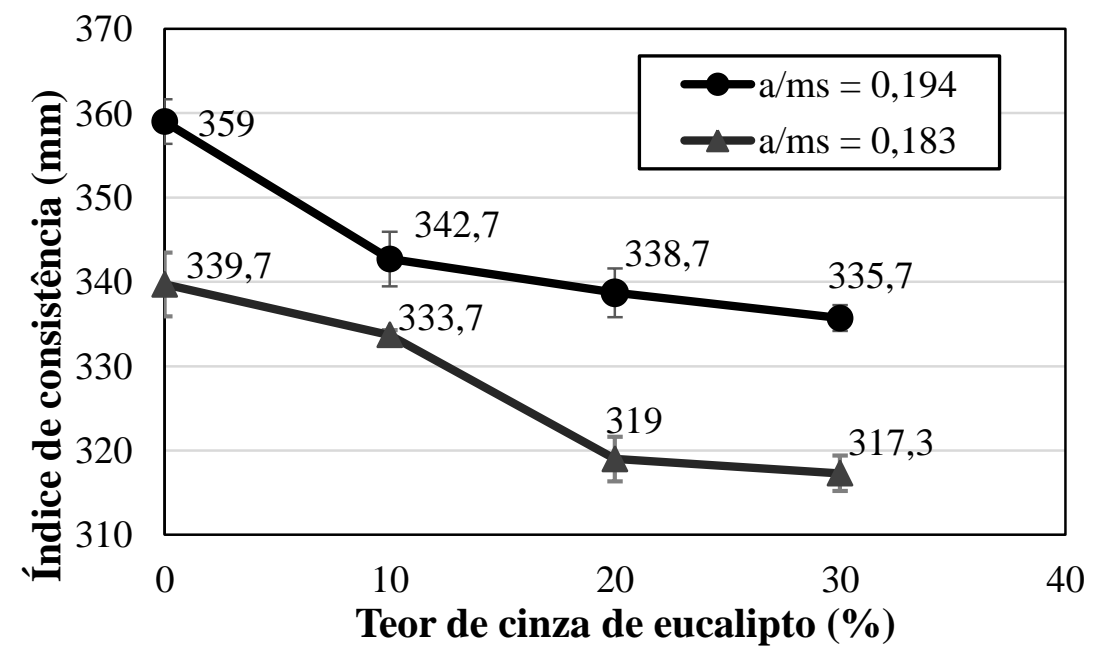


A Figura 8 apresenta os resultados de reologia das argamassas estudadas $(\mathrm{a} / \mathrm{ms}$ igual a 0,194$)$ com resultados do torque necessário para rotacioná-las, em função do tempo. As argamassas com substituição apresentaram maior plasticidade, bem como menor resistência ao cisalhamento em comparação à argamassa de referência, sendo a variação dessas propriedades função direta do teor de cinza utilizado.

$\mathrm{O}$ fato de a cinza de eucalipto possuir área superficial específica maior (partículas menores) do que o cimento poderia ocasionar menor fluidez nas argamassas em função de maiores teores de substituição, pois a inclusão de um material mais fino na mistura demanda maior quantidade de água para o molhamento total das partículas. Esse comportamento é observado no início do ensaio, quando o torque necessário foi maior com o aumento do teor de cinzas, o que está de acordo com os resultados reológicos monoponto, obtidos por meio da mesa de consistência (flow table) em um instante após a mistura e apresentados na Figura 7.

Depois desse momento e até o final dos $47 \mathrm{~min}$ de ensaio, o aumento no teor de partículas finas passou a facilitar a movimentação dos agregados e do cimento, permitindo o deslocamento da água e atuando como uma espécie de "lubrificante" entre as partículas maiores, a ponto de melhorar a reologia da mistura, conforme também foi observado nos trabalhos de Oliveira et al. (2000). Além disso, o aumento do teor de ar incorporado devido à adição das cinzas (Tabela 5) pode ter contribuído significativamente para a redução da consistência (Figura 7) e, consequentemente, do torque necessário para a mistura.

Por meio da aplicação do modelo de Bingham nos momentos de desaceleração do reômetro, foi possível calcular os parâmetros g e h, proporcionais à tensão de escoamento e à viscosidade respectivamente (Figuras 9 e 10). Os resultados obtidos pela aplicação do modelo de Bingham, de maneira análoga aos apresentados na Figura 2, mostram que as argamassas que contêm cinza de eucalipto apresentam menor tensão de escoamento e menor viscosidade quando comparadas às argamassas de referência. Comportamento semelhante foi verificado por Park et al. (2005), Zhang e Han (2000) e Ferraris et al. (2001).

Conforme observado na Figura 9, a tensão de escoamento foi menor para as argamassas com substituição do cimento pelas cinzas devido ao reduzido tamanho de partículas da cinza de eucalipto, de forma que maior é a distância interpartículas do sistema e menores são as forças de atrito restritivas ao fluxo da argamassa, sendo mais fácil deformá-la, e à maior incorporação de ar na mistura, conforme discutido anteriormente.

Figura 8 - Valores de torque para rotacionar as argamassas $(a / m s=0,194)$ em função do tempo e do teor de cinzas de eucalipto utilizado, em substituição ao cimento

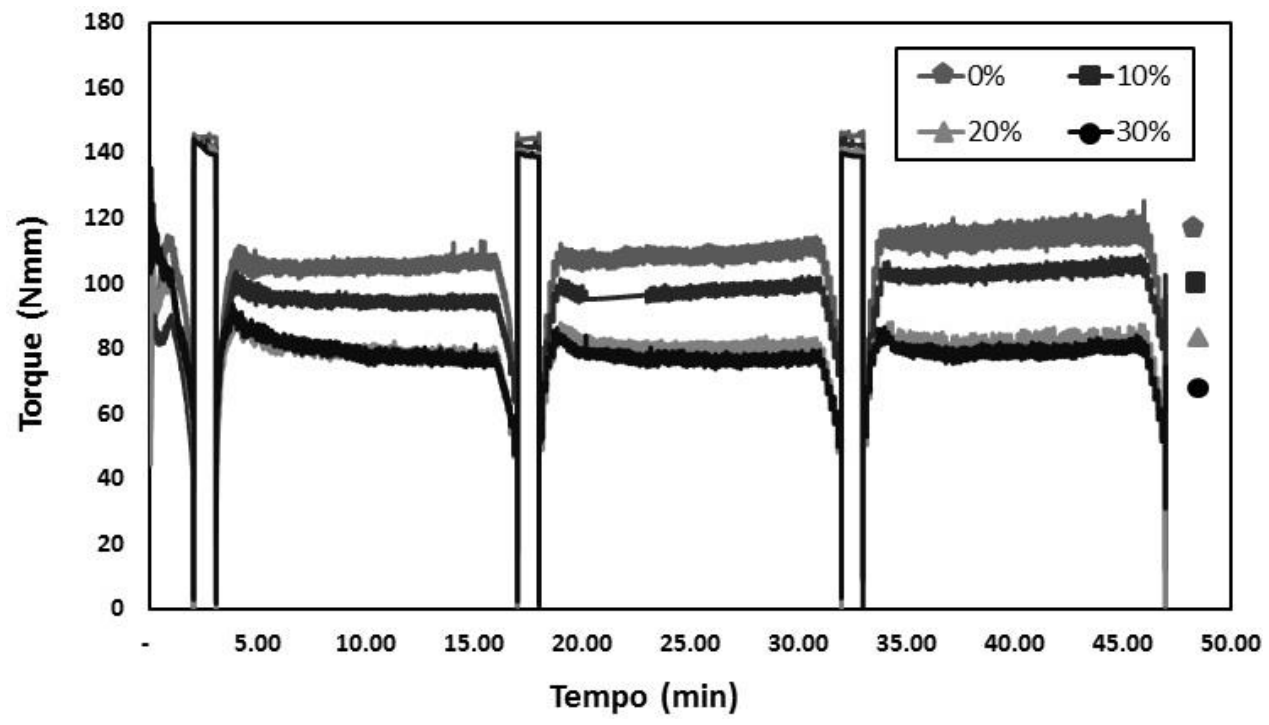

162 França, D. F. S.; Rey, R. O.; Ferreira, L. R. C.; Ribeiro, D. V. 
Figura 9 - Parâmetro g, proporcional à tensão de escoamento, em função do tempo e dos teores de substituição do cimento Portland por cinzas de eucalipto

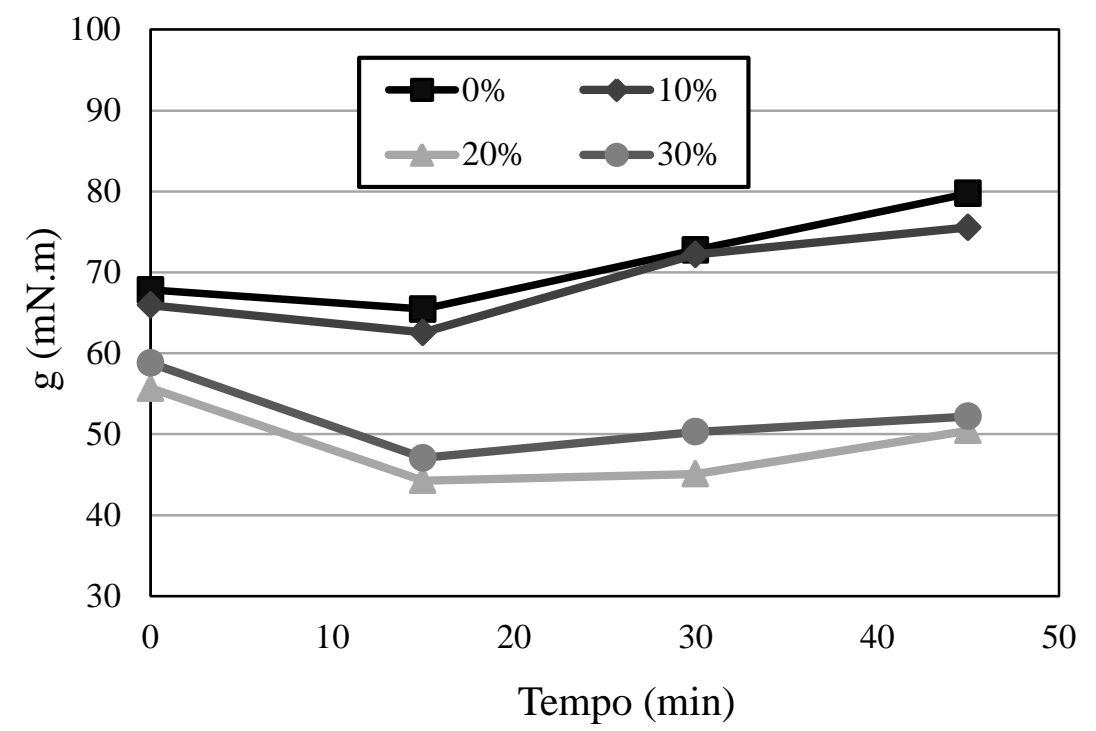

Figura 10 - Parâmetro $h$, proporcional à viscosidade, em função do tempo e dos teores de substituição do cimento Portland por cinzas de eucalipto

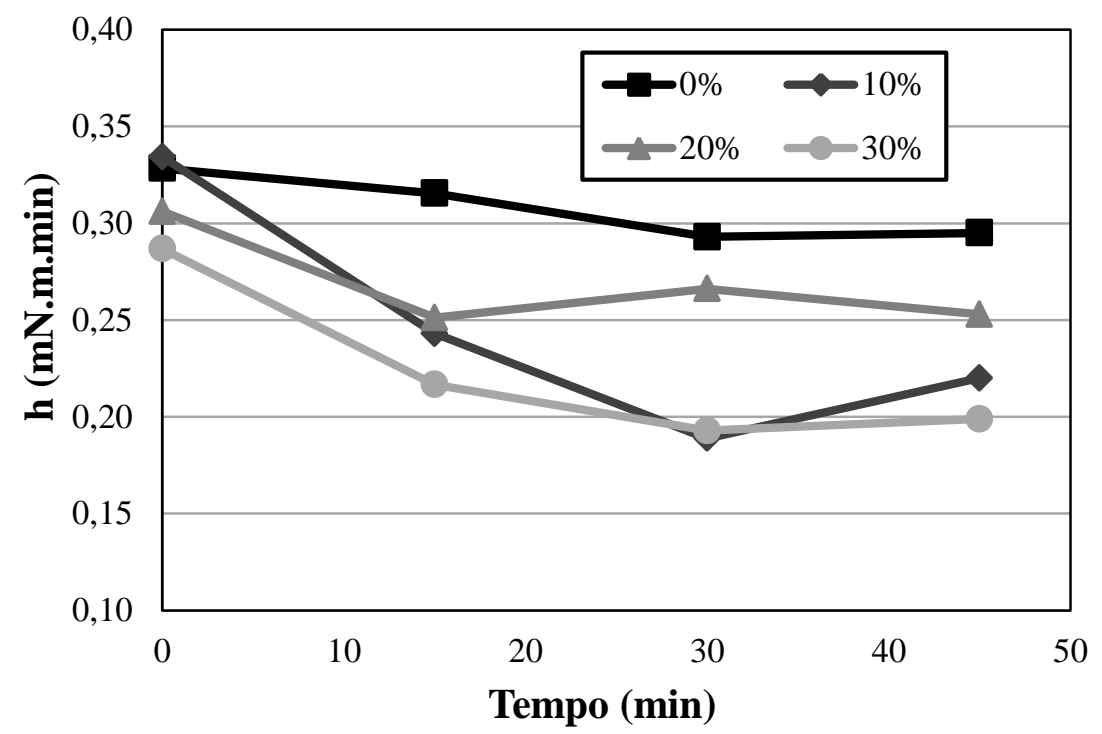

Após 15 min de mistura há queda na tensão de escoamento em todas as argamassas. Comportamento semelhante foi verificado em estudos de Antunes, John e Pilleggi (2005). De acordo com esses autores, a queda ocorre em virtude de a mistura ser mantida sob rotação, fazendo com que ela se torne mais homogênea e estável em relação a seu estado de dispersão, com a água recobrindo a superfície das partículas e preenchendo os vazios entre elas, o que também provoca maior distanciamento entre as unidades. Com o passar do tempo, as argamassas tiveram aumento gradual da tensão de escoamento devido às reações de hidratação do cimento.

Em conformidade com a Figura 8 (torque versus tempo), a viscosidade das argamassas (Figura 10) diminuiu em com $\mathrm{o}$ aumento do teor de substituição, devido ao efeito lubrificante das partículas finas. A tendência é a de diminuição da viscosidade das argamassas em função do tempo, pois as argamassas ficam sob cisalhamento com energia suficiente para quebrar os aglomerados formados. De acordo com Yang e Jennings (1995), com a diminuição dessas barreiras, as partículas 
fluem com maior facilidade, resultando na redução de sua viscosidade.

\section{Conclusões}

A partir dos resultados obtidos no presente trabalho, conclui-se que:

(c) a cinza de eucalipto possui características físicas adequadas para adição, que contribuem para uma maior densidade de empacotamento do sistema que as contenham, pois suas partículas são menores que as do cimento, ocorre ampla variedade de tamanho de partículas e estas são de formato predominantemente cúbico e prismático;

(d) a elevada área superficial das cinzas de eucalipto e seu teor de álcalis superior ao do cimento contribuem para o aumento na reação álcalis-agregado, o que deve ser ratificado por meio de ensaios mais aprofundados e, principalmente, de longa duração;

(e) devido ao fato de as cinzas apresentarem área superficial específica maior que o cimento e, consequentemente, demandar maior quantidade de água para o molhamento, argamassas que a contenham apresentam menor trabalhabilidade inicial, o que é observado por meio de ensaios na mesa de consistência (flow table); e

(f) a reologia das argamassas em função do tempo é significativamente alterada pela presença da cinza de eucalipto nas argamassas, pois o reduzido tamanho das partículas de cinza de eucalipto permite que a mesma atue como uma espécie de "lubrificante" da movimentação de partículas nos resultados obtidos por reometria, permitindo a melhoria da trabalhabilidade e da fluidez de forma diretamente proporcional ao aumento da substituição, além de maior incorporação de ar de mistura.

\section{Referências}

ALVES, N. J. D.; DO Ó, S. W. Aditivos Incorporadores de Ar e Retentores de Água. In: BAUER, E. (Org.). Revestimento de Argamassa: características e peculiaridades. Brasília: LEM, UnB, Sinduscon, 2005.

ANTUNES, R. P. N.; JOHN, V.; PILLEGGI, R. G. Influência da Sequência de Mistura nas Propriedades Reológicas de Argamassas Avaliada Por Squeeze-Flow. In: SIMPÓSIO BRASILEIRO DE TECNOLOGIA DE ARGAMASSAS, 6 , Florianópolis, 2005. Anais... Florianópolis, 2005.
ASSOCIAÇÃO BRASILEIRA DE NORMAS TÉCNICAS. NBR 7211: agregados para concreto: especificação. Rio de Janeiro, 2009.

ASSOCIAÇÃO BRASILEIRA DE NORMAS TÉCNICAS. NBR 9776: agregados: determinação da massa específica de agregados miúdos por meio de frasco Chapman. Rio de Janeiro, 1987.

ASSOCIAÇÃO BRASILEIRA DE NORMAS TÉCNICAS. NBR 5733: cimento Portland de alta resistência inicial. Rio de Janeiro, 1991.

\section{ASSOCIAÇÃO BRASILEIRA DE NORMAS TÉCNICAS. NBR NM 76: cimento Portland: determinação da finura pelo método de permeabilidade ao ar: método de Blaine. Rio de Janeiro, 1998.}

\section{ASSOCIAÇÃO BRASILEIRA DE NORMAS TÉCNICAS. NBR 13277: argamassa para assentamento e revestimento de paredes e tetos: determinação da densidade de massa e do teor de ar incorporado. Rio de Janeiro, 2005a.}

\section{ASSOCIAÇÃO BRASILEIRA DE NORMAS TÉCNICAS. NBR 13278: argamassa para assentamento de paredes e revestimento de paredes e tetos: determinação da densidade de massa e do teor de ar incorporado. Rio de Janeiro, 2005b.}

\section{ASSOCIAÇÃO BRASILEIRA DE NORMAS TÉCNICAS. NBR 13281: argamassa para assentamento e revestimento de paredes e tetos: requisitos. Rio de Janeiro, 2005c.}

\section{ASSOCIAÇÃO BRASILEIRA DE NORMAS TÉCNICAS. NBR 13276: argamassa para assentamento e revestimento de paredes e tetos: preparo da mistura e determinação do índice de consistência. Rio de Janeiro, 2010.}

\section{ASSOCIAÇÃO BRASILEIRA DE NORMAS TÉCNICAS. NBR 15577-4: agregados:} reatividade álcali-agregado: parte 4: determinação da expansão em barras de argamassa pelo método acelerado. Rio de Janeiro, 2008a.

\section{ASSOCIAÇÃO BRASILEIRA DE NORMAS TÉCNICAS. NBR 15577-1: agregados: reatividade álcali-agregado: parte 1: guia para avaliação da reatividade potencial e medidas preventivas para uso de agregados em concreto. Rio de Janeiro, 2008b.}

BANFILL, P. F. G. The Rheology of Fresh Cement and Concrete. Rheology Reviews, p. 91130, 2006.

BARBOSA, R. et al. Concretes Containing Biomass Ashes: mechanical, chemical, and ecotoxic performances. Construction and Building Materials,vn. 48, p. 457-463, 2013. 
BALANÇO ENERGÉTICO NACIONAL.

Relatório Final 2013. Disponível em:

<https://ben.epe.gov.br/>. Acesso em: 15 ago. 2014.

CABRERA, M. et al. Characterisation and Technical Feasibility of Using Biomass Bottom Ash for Civil Infrastructures. Construction and Building Materials, v. 58, p. 234-244, 2014.

CAMPOS, R. N. Durabilidade em Concretos Contendo Cinza de Biomassa Contendo Elevado Teor de Álcalis. Feria de Santana, 2015 Dissertação (Mestrado em engenharia Civil) Escola de Engenharia, Universidade Estadual de Feira de Santana, Feira de Santana, 2015.

CARASEK, H. Argamassas. In: ISAIA, G. C. (Org.). Materiais de Construção Civil e Princípios de Ciência e Engenharia de Materiais. São Paulo: Ibracon, 2007.

CARDOSO, F. Método de Formulação de Argamassas de Revestimento Baseado em Distribuição Granulométrica e Comportamento Reológico. Sáo Paulo, 2009. 138 f. Tese (Doutorado em Engenharia Civil) - Departamento de Engenharia de Construção Civil, Escola Politécnica da Universidade Federal de São Paulo, São Paulo, 2009.

FERRARIS, C. F. et al. The Influence of Mineral Admixtures on the Rheology of ceMent pasTe and Concrete. Cement and Concrete Research, v. 31, n. 2. p. 245-255, 2001.

KOEHLER, E. P.; FOWLER, D. W. Summary of Concrete Workability Test Methods. Austin? International Center for Aggregates Research, 2003.

KWAN, A. K. H.; LI, Y. Effects of Fly Ash Microsphere on Rheology, Adhesiveness and Strength of Mortar. Construction and Building Materials, v. 42, p. 137-145, 2013.

LODEIRO, I. G. et al. Alkali-Aggregate Reaction in Activated Fly ash Systems. Cement and Concrete Research, v. 37, n. 2, p. 175-183, 2007.

MASCHIO, S. et al. Fly and bottom Ashes From Biomass Combustion as Cement Replacing Components in Mortars Production: rheological behavior of the pastes and materials compression strength. Chemosphere, v. 85, n. 1. p. 666-671, 2011.

NAKAKURA, E. H.; CINCOTTO, M. A. Análise dos Requisitos de Classificação de Argamassas de Assentamento e Revestimento. São Paulo: Escola Politécnica da USP, 2004. (Boletim Técnico, n. 359).
OLIVEIRA, I. R. et al. Dispersão e

Empacotamento de Partículas: princípios e aplicações em processamento cerâmico. São Paulo: Fazendo Arte, 2000.

PARK, C. K. et al. Rheological Properties of Cementitious Materials Containing Mineral Admixtures. Cement and Concret Research, v. 35 , n. 5, p. 842-849, 2005.

RESENDE, D. S. Estudo do Efeito da Incorporação de Cinzas de Cavaco de Eucalipto Como Material Cimentício Suplementar. Ouro Preto, 2013. Tese (Doutorado em Engenharia Civil) - Programa de Pós-Graduação em Engenharia de Materiais, Universidade Federal de Ouro Preto, Ouro preto, 2013.

SCRIVENER, K. L.; KIRKPATRICK, R. J. Innovation in Use and Research on Cementitious Material. In: INTERNATIONAL CONGRESS OF CHEMISTRY OF CEMENT, 12., Montreal, 2007. Proceedings... Montreal, 2007.

SENFF, L.; HOTZA, D.; REPETTE, W. L. Comportamento Reológico de Pastas de Cimento Com Adição de Sílica Ativa, Nanossílica e Dispersante Policarboxílico. Revista Matéria, v. 15, n. 1, p. 12-20, 2010.

SHEHATA, M. H.; THOMAS, M. D. A. The Effect of Fly Ash Composition on the Expansion of Concrete Due to Alkali-Silica Reaction. Cement and Concrete Research, v. 30, p. 1063 1072, 2000.

SILVA, M. G. et al. Proposta Para Reaproveitamento de Resíduos Industriais da Região da Grande Vitória em Componentes Para a Construção Civil. In: ENCONTRO DE TECNOLOGIA NO AMBIENTE CONSTRUÍDO, São Paulo, 1993. Anais... São Paulo: ANTAC, 1993.

\section{SINDICATO NACIONAL DA INDÚSTRIA DO CIMENTO. Relatório Anual 2013. Disponível} em:

<http://www.snic.org.br/pdf/RelatorioAnual2013.p df $>$. Acesso em: 9 dez. 2014.

VASKE, N. R. Estudo Preliminar da Viabilidade do Aproveitamento da Cinza Proveniente de Filtro Multiciclone Pela Combustão de Lenha de Eucalipto em Caldeira Fumotubular Como Adição ao Concreto. Porto Alegre, 2012. Tese (Doutorado em Engenharia Civil) - Programa de Pós-Graduação em Engenharia Civil da Universidade Federal do Rio Grande do Sul, Porto Alegre, 2012. 
WANG, S.; BAXTER, L. Comprehensive Study of Biomass Fly Ash in Concrete: strength, microscopy, kinetics and durability. Fuel Processing Technology, v. 88, n. 11, p. 1165 1170, 2007.

YANG, M.; JENNINGS, H. M. Influences of Mixing Methods on the Microsture and Rheological Behavior of Cement Paste. Advanced Cement Based Materials, n. 2, p. 70-78, 1995.
ZHANG, X.; HAN, J. The Effect of Ultra-Fine Admixture on the Rheological Property of Cement Paste. Cement and Concret Research, v. 30, n. 5, p. 827-830, 2000.

\section{Agradecimentos}

À Fundação de Amparo à Pesquisa do Estado da Bahia (Fapesb), à Coordenação de Aperfeiçoamento de Pessoal de Nível Superior (Capes) e a Argamassas Contimassa - Argamassa Industrializada.

Débhora Flávia Soto França

Departamento de Ciência e Tecnologia dos Materiais, Escola Politécnica | Universidade Federal da Bahia | Rua Aristides Novis, $2,3^{\circ}$ andar, Federação | Salvador - BA - Brasil | CEP 40210-630 | Tel.: (71) 3283-9852 | E-mail: debhoraflavia@hotmail.com

Rafaela Oliveira Rey

Departamento de Ciência e Tecnologia dos Materiais, Escola Politécnica | Universidade Federal da Bahia | E-mail: rafaelarey2@gmail.com

Luciano Renato Conceição Ferreira

Departamento de Ciência e Tecnologia dos Materiais, Escola Politécnica | Universidade Federal da Bahia |

E-mail: lucianorenato11@hotmail.com

Daniel Veras Ribeiro

Departamento de Ciência e Tecnologia dos Materiais, Escola Politécnica | Universidade Federal da Bahia |

E-mail: verasribeiro@hotmail.com

\section{Revista Ambiente Construído}

Associação Nacional de Tecnologia do Ambiente Construído

Av. Osvaldo Aranha, $99-3^{\circ}$ andar, Centro

Porto Alegre - RS - Brasil

CEP 90035-190

Telefone: +55 (51) 3308-4084

Fax: +55 (51) 3308-4054

www.seer.ufrgs.br/ambienteconstruido

E-mail: ambienteconstruido@ufrgs.br 